\title{
Use of Fluorescent Indocyanine Green Angiography During Microsurgical Resection of a Recurrent Giant Perimedullary Cervical Spinal Arteriovenous Fistula in a Patient with Hereditary Hemorrhagic Telangiectasia
}

\author{
Omar Choudhri ${ }^{1}$, Jeremy J. Heit ${ }^{2}$, Mihir Gupta ${ }^{3}$, Michael P. Marks ${ }^{4}$, Robert Dodd \\ 1. Department of Neurosurgery, University of California - San Francisco 2. Department of Radiology, \\ Stanford University School of Medicine 3. Department of Neurosurgery, Stanford University School of \\ Medicine 4. Radiology, Stanford University School of Medicine 5.
}

$\square$ Corresponding author: Omar Choudhri, omar.choudhri@ucsf.edu

Disclosures can be found in Additional Information at the end of the article

\section{Abstract}

We report the utility of fluorescent indocyanine green (ICG) during the microsurgical resection of a giant perimedullary cervical arteriovenous fistula (GPMAVF) in a young man with hereditary hemorrhagic telangiectasia. ICG angiography is a useful adjunct for understanding angioarchitecture and drainage patterns in spinal arteriovenous malformation (AVM) surgery. Cervical GPMAVF is a rare spinal lesion found in association with hereditary hemorrhagic telangiectasia. This vascular malformation is associated with venous varices in a perimedullary location causing cord compression and vascular steal. This rare case highlights the crucial role of ICG during complex spinal AVM/AVF surgery to obtain angiographic cure.

Categories: Neurosurgery

Keywords: angiography, arteriovenous fistula, arteriovenous malformation, central nervous system vascular malformations, indocyanine green, spinal cord vascular diseases, telangiectasia, hereditary hemorrhagic

\section{Introduction}

Hemorrhagic telangiectasia (HHT), also known as Osler-Weber-Rendu syndrome, is an autosomal dominant disorder characterized by abnormal development of vasculature [1]. This disorder has a high penetrance, and patients present with multiple telangiectasias and arteriovenous malformations/fistulae (AVM/AVFs) [2]. The genetic mutations involve genes from the transforming growth factor (TGF) beta/bone morphogenic protein (BMP) superfamily, such as ENG (endoglin) and ALK-1 (activin receptor-like kinase) [3]. These genes are important in angiogenesis, and hence these patients develop mucocutaneous telangiectasias (including lips, tongue, oral cavity, and nose) and visceral AVMs (gastrointestinal, pulmonary, hepatic, cerebral, and spinal). Epistaxis and multiple mucocutaneous lesions are the most common presentation, and clinical diagnosis of HHT is based on the Curacao criteria [4]. Pulmonary AVMs are the most common visceral AVM in HHT patients, affecting as many as $37 \%-59 \%$ of adult HHT patients [1]. Spinal AVM/AVFs, a rare presentation of HHT, are seen in $4.5 \%-8 \%$ of patients according to the largest series [5-6].

How to cite this article

Choudhri O, Heit J J, Gupta M, et al. (June 19, 2014) Use of Fluorescent Indocyanine Green Angiography During Microsurgical Resection of a Recurrent Giant Perimedullary Cervical Spinal Arteriovenous Fistula in a Patient with Hereditary Hemorrhagic Telangiectasia. Cureus 6(6): e185. DOI 10.7759/cureus. 185 
Spinal AVMs in HHT patients are of a perimedullary type, which are AVFs supplied by radiculomedullary or radiculopial arteries with drainage into the intradural perimedullary veins. HHT patients can sometimes develop giant high-flow perimedullary fistulae marked by ectatic venous aneurysms that cause hemorrhage, venous hypertension, steal phenomena, or spinal cord mass effect [7]. HHT most often presents in the pediatric age group, but it may remain undiagnosed until adulthood. The treatment of these spinal perimedullary AVFs involves interruption of the fistula usually in the perimedullary location either by endovascular or microsurgical routes. The microsurgical approach involves laminectomy with intradural exposure of the perimedullary arteriovenous vascular network and dissection (cauterization and clipping of the point of fistula).

Fluorescent indocyanine green (ICG) angiography using an operative microscope is a critical adjunct in the microsurgical treatment of spinal AVMs in the current era. Intravenous injection of the ICG dye can identify the arterial feeders and venous drainage angioarchitecture, which allows understanding of the fistula point. The surgeon can therefore safely identify and obliterate the fistula.

We report the first case of a recurrent spinal giant perimedullary AVF (GPMAVF) in a young adult with HHT that was treated microsurgically using intraoperative fluorescent ICG angiography. ICG angiography helped reveal the fistula point near a large venous varix, allowing its successful treatment, which was confirmed by a subsequent conventional spinal angiogram.

Informed patient consent was obtained for all treatments.

\section{Case Presentation}

A 25-year-old right-handed male with a known history of HHT and a previously-treated spinal GPMAVF presented with symptoms of abnormal sweating/hyperhidrosis involving the left side of his face and neck. His first presentation six years prior at an outside hospital involved left neck pain and tingling in the left foot and neck. He was diagnosed with HHT given episodes of recurrent epistaxis in childhood, a positive family history of HHT in his mother and maternal grandmother, and the presence of cutaneous telangiectasias.

On initial clinical examination, he was found to have normal motor strength and sensation with hyperactive deep tendon reflexes and spinal scoliosis. Cutaneous and mucous membrane telangiectasias were also noted.

A complete spinal MRI demonstrated multiple flow voids in the cervical spinal cord extending from C4 to T2 with associated thinning of the cord and signal change. A large flow void consistent with a large venous varix was also noted at the C6 level. Given the MRI changes, a spinal angiogram was completed that showed a spinal GPMAVF (supplied by two large radiculopial feeders from the right thyrocervical trunk via the inferior thyroidal artery. There was additional supply via a small radiculopial feeder from the left vertebral artery. These three feeders joined to drain into a single hole fistula that drained into the giant venous varix and subsequently into the enlarged tortuous perimedullary venous plexus (Figure 1). Microsurgical clips from the prior surgery were seen during the angiogram that interrupted the previously present supply from the left thyrocervical branches. 


\section{Cureus}
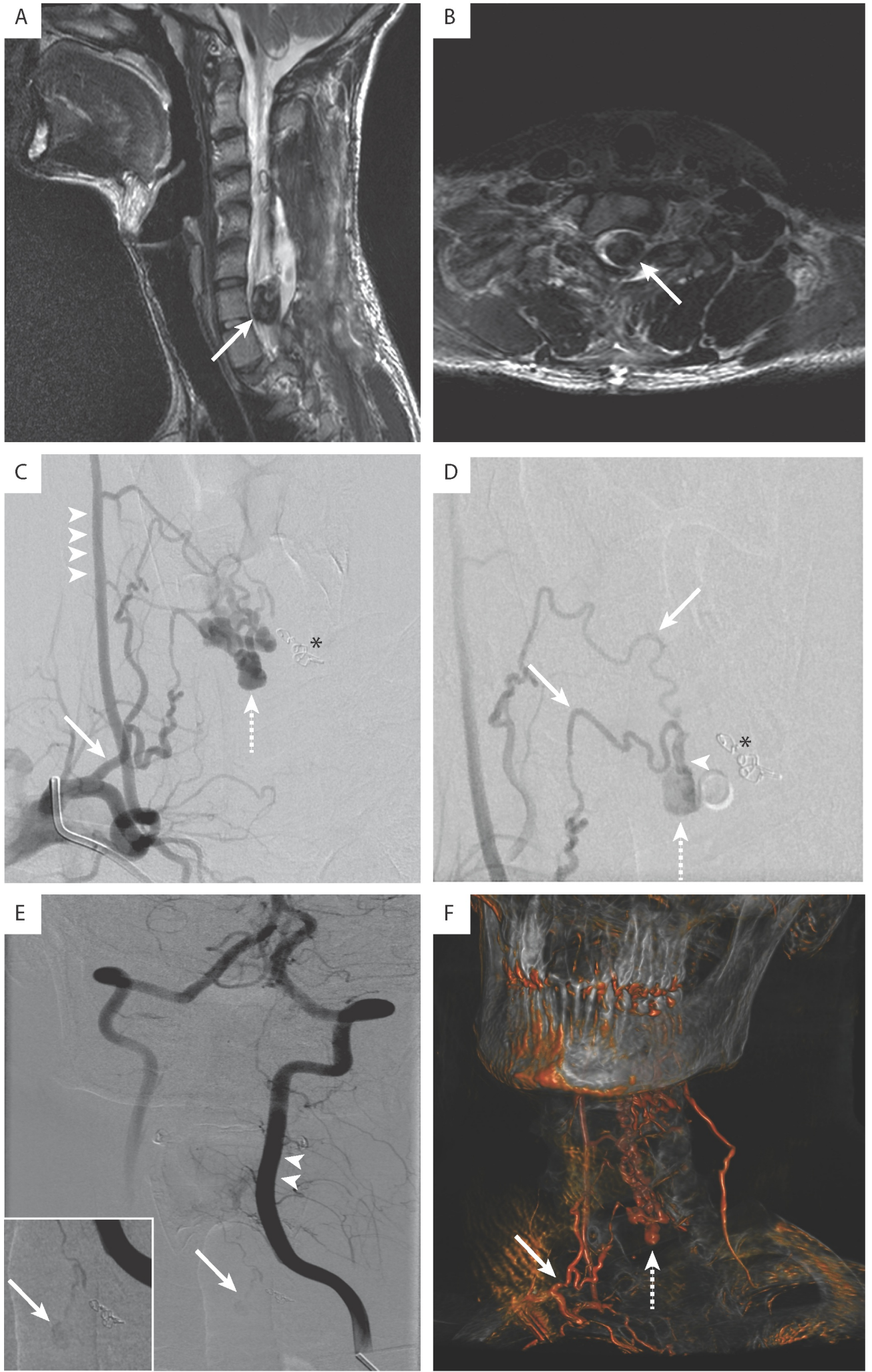

\section{FIGURE 1: Preoperative MRI and catheter angiography of}

\section{cervical spine perimedullary dural AVF}

(A, B) Sagittal (A) and axial (B) T2 weighted images demonstrate a heterogeneous hypointense venous varix (arrow) in the posterolateral perimedullary space at the level of the $C 7$ vertebral body. (C) Catheter injection of the right thyrocervical trunk demonstrates arteriovenous shunting within a perimedullary AVF. The AVF is located to the right of the prior surgical clips 


\section{Cureus}

(asterisk). The arterial supply is via an enlarged inferior thyroidal artery (arrow), which bifurcates into two branches, and the venous drainage is into a large venous varix (arrow with dashed lines). A prominent ascending cervical artery is indicated (arrowheads). (D) Magnified view of the AVF demonstrates two feeding arteries (arrows) that merge (arrowhead) just proximal to the fistula site that drains into the venous varix (arrow with dashed lines). Clips placed at the prior operation are noted (asterisk). (E) Catheter injection of the left vertebral artery (arrowheads) demonstrates arterial supply to the AVF (arrow) via small pial branches. Inset with a magnified image of the fistula (inset arrow) is also shown. (F) Reformatted image from a 3-D rotational angiogram demonstrating the arterial anatomy of the AVF with the arterial supply arising from the inferior thyroidal artery (arrow) and the venous drainage into a dilated varix (arrow with dashed lines).

We considered endovascular treatment, but given the tortuous course of the feeding radiculopial vessels, we felt that catheterization would be too high risk. Additionally, there was concern that glue cast in the venous varix could induce cord edema with deterioration of neurological function. We therefore proceeded with microsurgical treatment of the GPMAVF with intraoperative ICG assistance.

\section{Surgical technique}

The patient was placed under general endotracheal anesthesia. Following successful induction of anesthesia, baseline potentials were obtained with recording of EEG, SSEP, and EMG and motor-evoked potentials. The patient was then positioned on the operating room table in the prone position, and the fluoroscope was brought into the field to localize the appropriate spinal levels for surgery.

The old posterior cervical incision site was identified and marked. A midline incision was made, continued with muscle and soft tissue dissection to complete exposure from C3-C7. The location was again confirmed fluoroscopically, and the prior C3-C7 laminectomy was extended slightly caudally and cranially. Once adequate hemostasis was obtained, the dura was opened along the midline and tented laterally with 4-0 Surgilon suture. The arachnoid scar was lysed and dissected to untether the spinal cord. Multiple serpiginous dilated arterialized perimedullary veins that coursed superiorly were noted on the surface of the cord. There was also a globular venous varix with arterialized blood at the inferior aspect, laterally to the left.

\section{Microdissection and ICG use}




\section{Cureus}
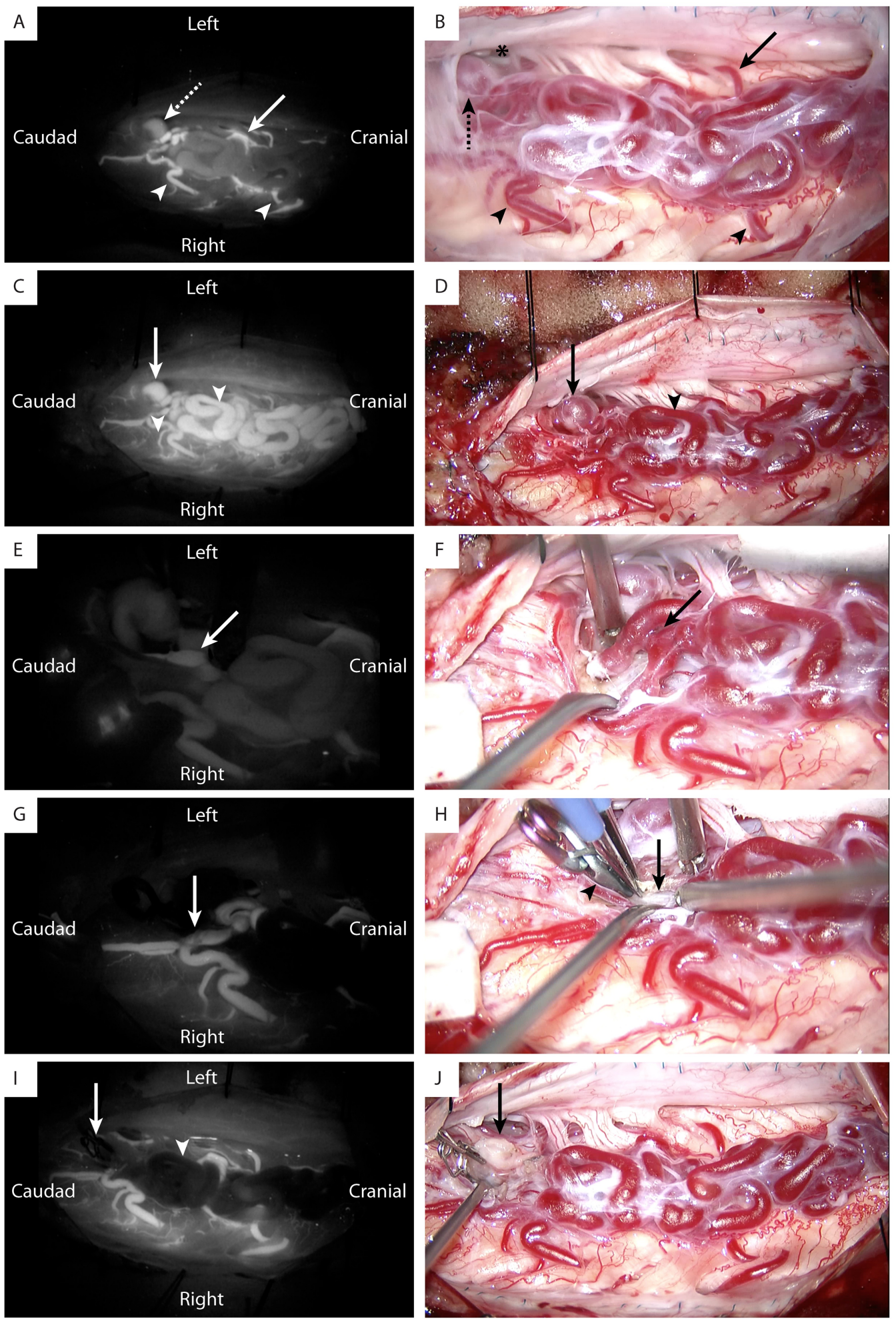

\section{FIGURE 2: Intraoperative ICG fluorescent angiography and}

corresponding operative microscopic images

(A, B) Early-arterial phase ICG (A) and microscopic (B) images demonstrate the arterial supply of the AVF, including two feeding arteries arising from the right inferior thyroidal artery (arrowheads) and a single feeding artery arising from the left vertebral artery (arrows). The venous varix just distal to the fistula site is also seen (arrows with dashed line). The previously placed surgical clip is also noted (asterisk). (C, D) Mid-arterial phase ICG (C) and microscopic

(D) images demonstrate a venous varix (arrows) and significant arteriovenous shunting into multiple dilated and tortuous pial veins (arrowheads). (E, F) Early-arterial phase magnified ICG 
(E) and microscopic $(F)$ images obtained after dissection demonstrate the fistula site (arrows). (G, H) Mid-arterial phase ICG (G) and microscopic images obtained after additional dissection demonstrate bipolar cauterization of the fistula site (arrows) after placement of a surgical clip (arrowhead in H). (I, J) Demagnified mid-arterial phase ICG (I) and microscopic (J) images after microsurgical clipping of the AVF demonstrate no residual filling of the dilated venous varix (arrows) or the pial veins (arrowhead in I).

A Leica M720 OH5 operating microscope (Leica Microsystems, Switzerland), including a near infrared camera with ICG functionality, was brought into the surgical field. Cottonoid patties were used to control any hemorrhage, and the focus was adjusted to visualize the malformation. After switching the microscope to ICG mode, $0.2-0.5 \mathrm{mg} / \mathrm{kg}$ of $0.25 \%$ ICG solution was injected intravenously. The arterial, capillary, and venous phases of the angiographic images were displayed on a screen in real time and simultaneously recorded with the microscope camera. ICG angiography demonstrated filling of the radiculopial arterial feeders, venous varix, and subsequent filling of the arterialized perimedullary veins. The overlying arterialized veins on the surface of the spinal cord hid the fistula point, and further dissection was done to follow the pial arterial feeders directly to the site of the fistula into the venous varix. After dissection, another ICG angiogram was performed, along with flow assessment, using a microvascular Doppler probe. This ultimately confirmed that the globular varix was not the primary site of the fistula but rather an adjacent smaller varix. After tracing the main feeding arteries, it was clear that they coursed from superior to inferior and from lateral to medial directly into the substance of the cord. Microvascular Doppler confirmed the additional varix within the substance of the cord. Having identified the site of the main arterial feeder, a second ICG angiogram was performed. The feeder was further dissected, clipped using a \#3 Sundt microsurgical clip, and coagulated. The lateral globular varix was also coagulated and shrunken. The microvascular Doppler signal within the veins in the varix was absent. An ICG angiogram was repeated. Again, this revealed fluorescence of the feeding arteries but no fluorescence within the venous varix or the arterialized veins. We then completed a watertight dural closure with intraoperative monitoring potentials remaining stable. The patient tolerated the procedure well and remained neurologically intact.

A spinal angiogram completed the following day showed no evidence of a residual AVF. There was no evidence of early venous drainage and no filling of the giant venous varix or the tortuous perimedullary veins (Figure 3).
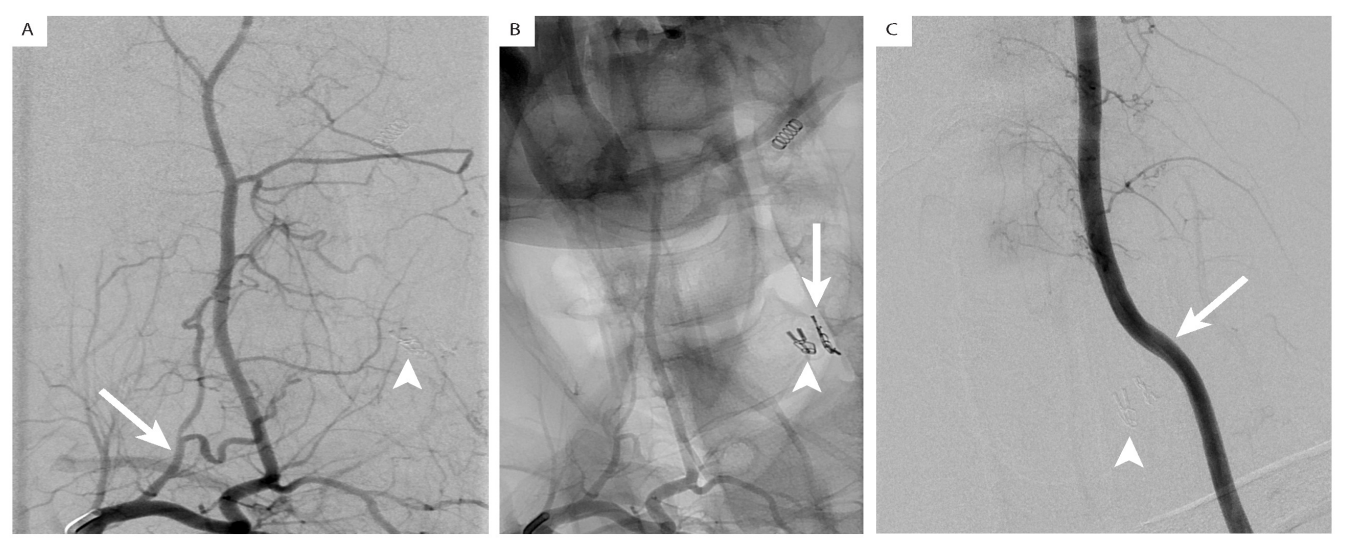

\section{FIGURE 3: Postoperative catheter angiography.}

(A) Catheter injection of the right thyrocervical trunk demonstrates no residual filling of the previously identified perimedullary AVF from the right inferior thyroidal artery (arrow). A new operative clip is indicated (arrowhead). (B) Unsubtracted image during catheter injection of the right thyrocervical trunk (same image as in panel A) demonstrates a new intradural operative 


\section{Discussion}

This is the first report in the literature describing the operative angioarchitecture and successful surgical treatment of a recurrent spinal GPMAVF in an adult with HHT using fluorescent ICG angiography. Perimedullary (Type IV) spinal AVFs were first described by Djindjian in 1977 [8]. These are characterized by arteriovenous shunts supplied by anterior or posterior spinal arteries and draining into the perimedullary venous plexus [9]. Type IVc constitute giant, high flow fistulae with multiple arterial feeders and large dilated and ectatic venous pockets [10]. Such GPMAVF are rare lesions that usually occur in the lumbar spine and conus medullaris area, and much less frequently in the cervical and thoracic spine. They are often associated with developmental vascular syndromes, such as HHT, Klippel-Trenauney syndrome, and Cobb syndrome, and are usually diagnosed in the pediatric age group [11]. Cervical GPMAVF are extremely rare. Of approximately 21 cases reported in the literature, most were treated endovascularly [12-19]. Amongst three recently reported cervical GPMAVF cases treated by surgery, two had failed endovascular treatment [11].

ICG is a synthetic near infrared fluorescent agent initially approved for systemic angiographic applications. Its use has since expanded to many neurosurgical applications, including aneurysmal, AVM, vascular tumor, and spinal vascular surgeries as well as extracranial/intracranial bypasses [9, 20-23]. In addition, ICG has been used to assess spinal cord perfusion and to resect vascular intramedullary lesions, such as cavernous malformations and hemangioblastomas [24-25]. Technical details of ICG fluorescent angiography have been described elsewhere [26]. Intraoperative video ICG for a spinal vascular lesion has many advantages. ICG allows temporal resolution of the angiographic anatomy of spinal AVMs, does not involve exposure to iodinated contrast or radiation, can be given intravenously and multiple times during surgery, and helps the surgeon discern the fistula point, arterial feeders, and the venous drainage patterns in real time. Furthermore, it can be recorded and reviewed by the surgeon in detail during the course of surgery. Some disadvantages of ICG are that vessels covered by tissue, obscured by blood, or outside the surgical field are not visualized.

Additionally, there might be delay in the clearance of ICG from the venous shunt lesion. This may make understanding of arteriovenous shunts harder in AVM/AVF surgery where multiple ICG injections might be performed over the course of resection [27].

Hanel, et al. reported their experience using ICG during resection of six patients with Type I spinal dural AVFs (dAVFs) [28]. They were able to demonstrate the precise recognition by ICG of the radiculomeningeal feeders supplying these fistulae. They encountered no residual fistulae on postoperative angiography and no complications were encountered from ICG use. More recently, Walsh, et al. reported that ICG-facilitated surgical obliteration of spinal AVFs, including four Type IV perimedullary spinal AVFs (located in the conus in one, in the lumbar region in another, and at unspecified locations in two patients) [9]. ICG also helped locate the patent component of an AVM nidus in a partially thrombosed AVM in one case.

In most cases, ICG is administered intravenously where it is diluted by the systemic circulation and carried by arterial flow to the site of observation. Some studies state that intra-arterial injection of ICG provides a better temporal resolution of flow dynamics and has a faster washout [29-30]. However, one limitation of selective intra-arterial ICG injection is that it may miss identification of the multiple, possibly bilateral, arterial feeders that supply GPMAVFs, as were present in our patient. 
In patients with HHT, spinal AVFs are classically perimedullary macrofistulae supplied by radiculomedullary and radiculopial vessels. Given the size of these venous varices, patients almost always present in early childhood with hemorrhage and paraplegia, and ultimately develop significant mass effect and myelopathy if the AVF is inadequately treated.

Our patient presented with myelopathic features alone, and at an unusually late age (19 years), likely because he was one of the few such patients in whom the AVF did not hemorrhage in childhood. He was initially treated by surgical clipping of the single pial feeder from the left thyrocervical trunk. These perimedullary fistulae can easily be misconstrued as "dural" arteriovenous fistulae, which is what happened in our patient's case. The surgeon had ligated the main arterial feeder but the fistula was not disconnected. The clip from the prior operation was seen next to the dural entry of the pial vessel, which was not the site of the fistula.

The patient improved temporarily until the fistula recruited additional feeders from the left vertebral artery and the right inferior thyroidal artery in the ensuing years, possibly facilitated by the abnormal angiogenic microenvironment present in HHT [31-32]. This surgery occurred when ICG was unavailable; hence, no appreciation of the fistula site was made intraoperatively. During the second surgery at our center, the availability of ICG technology was extremely useful as it allowed us to identify the three pial arterial feeders supplying the fistula. The temporal appearance and disappearance of fluorescent dye during the early, mid, and late arterial phases allowed us to locate the fistula site adjacent to the venous varix. A total of four ICG runs were completed during the course of dissection until we were able to dissect onto the fistula vessel.

A large portion of the venous varix was covered with cord tissue, and we were able to detect a Doppler signal in that portion. Not being able to appreciate the covered portion of a vascular malformation by ICG is a disadvantage of ICG technology. Authors have alluded to this limitation while dealing with Type II glomus AVMs, and surgeons can overlook a nidus if not seen on ICG. This was the experience of Halbach, et al. in their series where a fistula hole could not be interrupted directly because it was covered by spinal cord tissue [13]. We found microvascular Doppler to be extremely helpful in this situation, as signal was detected through cord tissue. ICG, in combination with microvascular Doppler, can therefore help surgeons definitively treat these more challenging spinal perimedullary fistulae and thus provide confidence to the surgeon intraoperatively.

Spinal vascular malformations can be treated endovascularly, surgically, or by both methods. Outcomes from each modality can be similar at experienced centers, but selection of therapy for perimedullary AVF remains an area of controversy [12]. A number of case reports and small case series have described endovascular treatment of GPMAVFs [8, 15, 33]. The largest series of children treated for neurovascular manifestations of HHT included seven with spinal AVFs, and all were treated endovascularly using glue embolization with a success rate of $>90 \%$ [33]. We considered the endovascular route for treatment of our patient, but given the tortuosity of the pial feeders, we did not believe we could get adequate glue penetration or get close enough to the fistula pocket to deposit coils. There is additional well-founded concern that depositing an embolic agent inside the venous varix can cause swelling of an already compressed spinal cord. One series experienced temporary post-procedural deterioration in some of these patients, which subsequently improved. Nagashima, et al. reported neurologic deterioration in a 16year-old three weeks after initial improvement following transarterial embolization of a giant cervical perimedullary AVF [16]. This deterioration was thought to be propagated by the thrombus in the venous lakes, which was causing pressure on the compromised cord. Surgical excision of the thrombosed venous varix was required to relieve the pressure and improve symptoms.

\section{Conclusions}


GPMAVFs in the cervical spine are extremely rare lesions that can present with myelopathy and hemorrhage. These single fistula lesions may be associated with HHT. If more commonly used endovascular interventions are not feasible or fail, microsurgical extirpation can be challenging. Robust recurrent vascularization of the fistula after endovascular or surgical treatment may be stimulated by the angiogenic microenvironment present in developmental vascular disorders, such as HHT. We describe our experience with the use of fluorescent ICG video-angiography in an adult HHT patient with a cervical GPMAVF that recurred six years after initial surgical ligation of the original arterial feeder. This fluorescent technology assisted our successful curative treatment of the lesion through improved understanding of fistula angioarchitecture. We recommend that this technology to be routinely used in patients with complex spinal vascular malformations, particularly in cases where secondary revascularization of the AVF occurs in the setting of HHT and other inherited vascular conditions with aberrant angiogenesis.

\section{Additional Information \\ Disclosures}

Human subjects: Consent was obtained by all participants in this study. Conflicts of interest: In compliance with the ICMJE uniform disclosure form, all authors declare the following:

Payment/services info: All authors have declared that no financial support was received from any organization for the submitted work. Financial relationships: All authors have declared that they have no financial relationships at present or within the previous three years with any organizations that might have an interest in the submitted work. Other relationships: All authors have declared that there are no other relationships or activities that could appear to have influenced the submitted work.

\section{Acknowledgements}

We thank Cindy H. Samos for her assistance with preparation of this manuscript.

\section{References}

1. McDonald J, Bayrak-Toydemir P, Pyeritz RE: Hereditary hemorrhagic telangiectasia: An overview of diagnosis, management, and pathogenesis. Genet Med. 2011, 13:607-16. 10.1097/GIM.0b013e3182136d32

2. Begbie ME, Wallace GM, Shovlin CL: Hereditary haemorrhagic telangiectasia (Osler-WeberRendu syndrome): A view from the 21st century. Postgrad Med J. 2003, 79:18-24.

3. Pawlikowska L, Tran MN, Achrol AS, Ha C, Burchard E, Choudhry S, Zaroff J, Lawton MT, Castro R, McCulloch CE, Marchuk D, Kwok PY, Young WL: Polymorphisms in transforming growth factor-beta-related genes ALK1 and ENG are associated with sporadic brain arteriovenous malformations. Stroke. 2005, 36:2278-80.

4. Poisson A, Vasdev A, Brunelle F, Plauchu H, Dupuis-Girod S; French Italian HHT network: Acute paraplegia due to spinal arteriovenous fistula in two patients with hereditary hemorrhagic telangiectasia. Eur J Pediatr. 2009, 168:135-9. 10.1007/s00431-008-0863-2

5. Roman G, Fisher M, Perl DP, Poser CM: Neurological manifestations of hereditary hemorrhagic telangiectasia (Rendu-Osler-Weber disease): Report of 2 cases and review of the literature. Ann Neurol. 1978, 4:130-44.

6. Mahadevan J, Ozanne A, Yoshida Y, Weon YC, Alvarez H, Rodesch G, Lasjaunias P: Hereditary Haemorrhagic Telangiectasia Cerebrospinal Localization in Adults and Children. Review of 39 cases. Interv Neuroradiol. 2004, 10:27-35.

7. Mont'Alverne F, Musacchio M, Tolentino V, Belzile F, Riquelme C, Tournade A: Giant spinal perimedullary fistula in hereditary haemorrhagic telangiectasia: diagnosis, endovascular treatment and review of the literature. Neuroradiology. 2003, 45:830-6.

8. Djindjian M, Djindjian R, Rey A, Hurth M, Houdart R: Intradural extramedullary spinal arteriovenous malformations fed by the anterior spinal artery. Surg Neurol. 1977, 8:85-93. 
9. Walsh DC, Zebian B, Tolias CM, Gullan RW: Intraoperative indocyanine green videoangiography as an aid to the microsurgical treatment of spinal vascular malformations. $\mathrm{Br}$ J Neurosurg. 2014, 28:259-66. 10.3109/02688697.2013.829556

10. Anson JA, Spetzler RF: Classification of spinal arteriovenous malformations and implications for treatment. BNI Quarterly. 1992, 8:2-8.

11. Casasco A, Guimaraens L, Senturk C, Cotroneo E, Gigli R, Theron J: Endovascular treatment of cervical giant perimedullary arteriovenous fistulas. Neurosurgery. 2012, 70:141-149. 10.1227/NEU.0b013e31822ec19e

12. Cho KT, Lee DY, Chung CK, Han MH, Kim HJ: Treatment of spinal cord perimedullary arteriovenous fistula: Embolization versus surgery. Neurosurgery. 2005, 56:232-41.

13. Halbach VV, Higashida RT, Dowd CF, Fraser KW, Edwards MS, Barnwell SL: Treatment of giant intradural (perimedullary) arteriovenous fistulas. Neurosurgery. 1993, 33:972-9.

14. Ioannidis I, Sfakianos G, Nasis N, Prodromou P, Andreou A: Successful embolization of a giant perimedullary arteriovenous fistula of the cervical spine in a 6-year-old child. Childs Nerv Syst. 2007, 23:1327-30.

15. Mourier KL, Gobin YP, George B, Lot G, Merland JJ: Intradural perimedullary arteriovenous fistulae: results of surgical and endovascular treatment in a series of 35 cases. Neurosurgery. 1993, 32:885-91.

16. Nagashima C, Miyoshi A, Nagashima R, Ogawa M, Enomoto K, Watabe T: Spinal giant intradural perimedullary arteriovenous fistula: clinical and neuroradiological study in one case with review of literature. Surg Neurol. 1996, 45:524-31.

17. Riche MC, Modenesi-Freitas J, Djindjian M, Merland JJ: Arteriovenous malformations (AVM) of the spinal cord in children. A review of 38 cases. Neuroradiology. 1982, 22:171-80.

18. Ricolfi F, Gobin PY, Aymard A, Brunelle F, Gaston A, Merland JJ: Giant perimedullary arteriovenous fistulas of the spine: clinical and radiologic features and endovascular treatment. AJNR Am J Neuroradiol. 1997, 18:677-87.

19. Sasamori T, Hida K, Yano S, Asano T, Iwasaki Y: Cervical perimedullary arteriovenous fistula in an infant presenting with subarachnoid hemorrhage--case report. Neurol Med Chir (Tokyo). 2008, 48:409-13.

20. De la Garza-Ramos R, Bydon M, Macki M, Huang J, Tamargo RJ, Bydon A: Fluorescent techniques in spine surgery. Neurol Res. 2014, in press:

21. Ng YP, King NK, Wan KR, Wang E, Ng I: Uses and limitations of indocyanine green videoangiography for flow analysis in arteriovenous malformation surgery. J Clin Neurosci. 2013, 20:224-32. 10.1016/j.jocn.2011.12.038

22. Tsuzuki S, Aihara Y, Eguchi S, Amano K, Kawamata T, Okada Y: Application of indocyanine green (ICG) fluorescence for endoscopic biopsy of intraventricular tumors. Childs Nerv Syst. 2014, 30:723-6.

23. Washington CW, Zipfel GJ, Chicoine MR, Derdeyn CP, Rich KM, Moran CJ, Cross DT, Dacey RG Jr: Comparing indocyanine green videoangiography to the gold standard of intraoperative digital subtraction angiography used in aneurysm surgery. J Neurosurg. 2013, 118:420-7. 10.3171/2012.10.JNS11818

24. Endo T, Aizawa-Kohama M, Nagamatsu K, Murakami K, Takahashi A, Tominaga T: Use of microscope-integrated near-infrared indocyanine green videoangiography in the surgical treatment of intramedullary cavernous malformations: Report of 8 cases. J Neurosurg Spine. 2013, 18:443-9. 10.3171/2013.1.SPINE12482

25. Hao S, Li D, Ma G, Yang J, Wang G: Application of intraoperative indocyanine green videoangiography for resection of spinal cord hemangioblastoma: Advantages and limitations. J Clin Neurosci. 2013, 20:1269-75. 10.1016/j.jocn.2012.12.008

26. de Oliveira JG, Beck J, Seifert V, Teixeira MJ, Raabe A: Assessment of flow in perforating arteries during intracranial aneurysm surgery using intraoperative near-infrared indocyanine green videoangiography. Neurosurgery. 2008, 62:1300-10.

10.1227/01.neu.0000333795.21468.d4

27. Oh JK, Shin HC, Kim TY, Choi GH, Ji GY, Yi S, Ha Y, Kim KN, Yoon DH: Intraoperative indocyanine green video-angiography: Spinal dural arteriovenous fistula. Spine (Phila Pa 1976). 2011, 36:E1578-80. 10.1097/BRS.0b013e318213c41e

28. Hanel RA, Nakaji P, Spetzler RF: Use of microscope-integrated near-infrared indocyanine green videoangiography in the surgical treatment of spinal dural arteriovenous fistulae. Neurosurgery. 2010, 66:978-84. 10.1227/01.NEU.0000368108.94233.22 


\section{Cureus}

29. Kono K, Uka A, Mori M, Haga S, Hamada Y, Nagata S: Intra-arterial injection of indocyanine green in cerebral arteriovenous malformation surgery. Turk Neurosurg. 2013, 23:676-9.

10.5137/1019-5149.JTN.6420-12.0

30. Yamamoto S, Kim P, Kurokawa R, Itoki K, Kawamoto S: Selective intraarterial injection of ICG for fluorescence angiography as a guide to extirpate perimedullary arteriovenous fistulas. Acta Neurochir (Wien). 2012, 154:457-63. 10.1007/s00701-011-1223-y

31. Zucco L, Zhang Q, Kuliszewski MA, Kandic I, Faughnan ME, Stewart DJ, Kutryk MJ: Circulating angiogenic cell dysfunction in patients with hereditary hemorrhagic telangiectasia. PLoS One. 2014, 9:e89927. 10.1371/journal.pone.0089927

32. Choi EJ, Kim YH, Choe SW, Tak YG, Garrido-Martin EM, Chang M, Lee YJ, Oh SP: Enhanced responses to angiogenic cues underlie the pathogenesis of hereditary hemorrhagic telangiectasia 2. PLoS One. 2013, 8:e63138. 10.1371/journal.pone.0063138

33. Barrow DL, Colohan AR, Dawson R: Intradural perimedullary arteriovenous fistulas (type IV spinal cord arteriovenous malformations). J Neurosurg. 1994, 81:221-9. 